\title{
Bruni
}

\section{O sentido da docência formadora}

\author{
MARILENA CHAUI
}

RESUMO: A autora faz um retrato intelectual de José Carlos Bruni, destacando seu perfil acadêmico humanista e sua interpretação do pensamento de Augusto Comte, na qual Bruni reconstrói a problemática da ordem e do autoritarismo na modernidade.

PALAVRAS-CHAVE: docência, universidade, positivismo, Augusto Comte, sociologia.

a universidade operacional, em que estamos jogados como numa vala comum, não há lugar para a docência como valor primeiro da atividade universitária. Há, porém, os que navegam contra a corrente e não se deixam intimidar pelos ares do tempo. José Carlos Bruni é um deles.

Fui colega de Bruni na graduação e na pós-graduação de filosofia, no final dos anos 50 e início dos 60, na Rua Maria Antônia. Freqüentamos um Departamento de Filosofia em que eram poucos os alunos e poucos os professores, eram poucas as disciplinas e poucas as horas-aula por disciplina. Fomos poupados das doações advindas do "milagre brasileiro", isto é, da massificação, pomposamente designada pela ditadura com o nome de "democratização do ensino", como se uma ditadura pudesse produzir efeitos democráticos. Fomos por isso poupados da orgia burocrática dos cursos semestrais, dos créditos, da multiplicação de disciplinas e de sua divisão em obrigatórias e optativas e da dispersão que, hoje, nos tolhe o trabalho e desorienta os estudantes. Somos de um tempo em que as aulas eram magistrais, cuidadosamente preparadas e ministradas como pequenas obras de arte, momento de expressão da atividade de pesquisa de nossos 
professores e de aprendizado formador para os alunos. De um tempo em que os seminários eram nossa iniciação à pesquisa e em que nos preparávamos para lecionar filosofia no colegial (batizado, depois, de segundo grau e ensino médio). Essa dedicação e esse gosto pela docência deixaram marcas indeléveis no professor Bruni.

Colegas de graduação e de pós-graduação, Bruni e eu perdemos contacto por alguns anos, pois ele foi para Alemanha como bolsista e eu, para a França, também como bolsista. Regressando ao Brasil, foi para UNESP enquanto eu ficaria na USP. Só muitos anos depois, voltamos a nos encontrar, em debates sobre a burocracia e a universidade, feitos em São Paulo e no interior. Da UNESP, Bruni veio para a USP, para o Departamento de Ciências Sociais, e, com a reformulação departamental, para o de Sociologia. Aqui, nosso reencontro resultou em algo paradoxal: tendo defendido o mestrado na Alemanha, Bruni deveria fazer o doutoramento no Brasil, orientado por um de nossos antigos professores, mas a cassação destes pela ditadura fez com que, ao fim e ao cabo, eu me tornasse formalmente orientadora de José Carlos! Enfatizo o formalmente, pois não só não teria propósito eu "orientar" Bruni, como também foi ele, sem sombra de dúvida, quem me ensinou a ler a obra de Augusto Comte. Em poucas palavras: o doutoramento foi o trabalho de um espírito independente, maduro, rigoroso e criativo. E de um pesquisador coerente: professor de cursos para estudantes de Ciências Sociais (na UNESP e na USP), Bruni, que estudara em Marx a questão da ideologia, dedicou-se à origem da sociologia, expressão maior da ideologia burguesa, escrevendo sobre o pensamento de seu fundador.

De fato, sua tese de doutoramento explora a articulação estabelecida por Comte entre a ciência e o poder, mostrando que essa articulação não se realiza extrinsecamente, mas na própria definição e desenvolvimento dos termos que deram origem à sociologia, isto é, os conceitos de crise (a divisão e cisão do social, a revolução) e ordem (a unidade orgânica e harmoniosa do social, a estabilidade, hierarquia e autoridade). Rompendo com uma tradição interpretativa que se inicia no séc. XIX, na qual o positivismo comteano aparece dividido entre uma epistemologia (que funda o conceito contemporâneo de ciência e uma ciência nova, a sociologia) e uma política utópica, romântica e um tanto risível (quem levaria a sério, num tempo de ciência positiva, a Religião da Humanidade?), Bruni retoma a afirmação de Comte de que o positivismo "se compõe essencialmente de uma filosofia e de uma política necessariamente inseparáveis", mostrando que epistemologia e política são concomitantes e, mais do que isso, a segunda funda a primeira, pois é o diagnóstico comteano da política que determina sua idéia de ciência. Com efeito, o conceito positivista de ciência funda-se na idéia de ordem objetiva ou ordem universal, sem a qual não se poderia falar em invariabilidade das leis naturais e previsibilidade dos fenômenos, e essa idéia, indissociável da de crise, é política.

Isso significa que, em lugar de tomar cronologicamente a obra de Comte, indo do Curso de Filosofia Positiva ao Sistema de Política Positiva, Bruni faz o caminho inverso, encontrando no segundo o sentido do 
primeiro, propondo "a inversão do sujeito e do predicado, necessária a uma leitura que se define como crítica da ideologia”. Dessa maneira, Bruni pode mostrar que não há no positivismo uma teoria da ciência, mas uma descrição e classificação dos procedimentos científicos que visa conferir poder aos cientistas. Todavia, esse poder não tem como lugar próprio o Estado nem as instituições políticas, mas se define como poder da inteligência e da moralidade, de onde emana o "governo da opinião". Em outras palavras, a política é um invisível que se efetiva pela moral e esta, por seu turno, é a ciência da submissão do indivíduo à ordem social. De Comte a Durkheim nenhum passo precisa ser dado.

Distanciando-se das críticas de ideologia propostas pela Escola de Frankfurt e por Althusser, aproximando-se das arqueologias do poder, de Foucault, e da análise da ideologia burguesa proposta por Lefort, Bruni explicita o sentido do lugar da biologia no sistema positivista. De fato, é um lugar comum na interpretação da obra comteana e da sociologia apontar o papel fundante do modelo biológico, os intérpretes sublinhando o organicismo funcionalista. Não é isso que Bruni sublinha e sim a articulação entre a biologia e a marca principal da ideologia burguesa, qual seja, um discurso criador de normas. Ora, a biologia, para Comte, exprime a ordem não como arranjo funcional das partes e sim como comando das partes segundo a norma, entendida como funcionamento normal. A biologia oferece, portanto, as leis do funcionamento normal da inteligência e o positivismo pode oferecer as leis do funcionamento normal da razão humana e ser "a figuração da normalidade". De onde vem essa visão da biologia como sistema de comando e normalização? Do fato de que a idéia de ordem é originariamente (isto é, em Roma) um conceito militar referido à hierarquia de comando e obediência, à disciplina e à autoridade. Compreendida em seu sentido primeiro, a ordem, acrescida da dimensão biológica, torna compreensível a afirmação positivista de que a sociedade industrial é a sociedade positiva ou científica, pois, como industrial, é a norma funcionalmente observada, e, como militar, é a norma como princípio de organização do poder.

No entanto, parece haver algo paradoxal no discurso de Comte, pois não se apresenta como discurso do consenso, da harmonia e da unidade e sim da força, da violência fundadora da sociedade burguesa. A paciente análise dialética de Bruni desfaz o paradoxo para revelar a necessidade que comanda esse discurso: o pensamento de Comte opera com pares e com a passagem de um termo a outro; nessa dualidade, o primeiro termo é posto como essência constituída e ponto de partida, enquanto o segundo termo é a modificação superior do primeiro, "como um sujeito que corrige o objeto" porque o sujeito sempre esteve ali, escondido, portador da verdade do objeto. Ao desvendar o modo de construção do discurso positivista, Bruni não só nos deixa ver porque é preciso começar pelo Sistema para compreender o Curso, como ainda nos faz compreender porque o senso-comum popular e a desordem política são os termos principais de onde Comte parte para chegar à idéia de ciência e fundar a sociologia. O par crise-ordem culmina na idéia de "estado normal da humanidade", em que o "normal" exclui o 
"patológico" num perfeito sistema de controle social, político, cultural e ideológico, na "mais perfeita engenharia dos processos de exclusão social", inaugurando um novo modo de pensar: o moderno autoritarismo.

Não por acaso, o professor Bruni ofereceu, como optativa no curso de Sociologia, uma disciplina denominada "Sociologia da Desordem". E também não por acaso, fez a mais aguda crítica à palavra de ordem "transição democrática" (em voga no início dos anos 80 brasileiros), mostrando que não pode haver "transição" da ditadura para a democracia, pois a idéia de transição, ao marcar o tempo com o selo da continuidade progressiva ou evolutiva, faz supor que a democracia está potencialmente ou virtualmente contida na ditadura ou que esta evolui e progride rumo à democracia. Em outras palavras, a diferença radical entre ditadura e democracia é apagada e esse apagamento não é inocente nem ingênuo, mas uma posição política definida com conseqüências históricas.

Quem conhece a vida acadêmica de Bruni não pode deixar de observar o lugar preponderante que a docência tem em seu trabalho, seja diretamente como professor e conferencista, seja indiretamente como editor de revistas para difusão dos trabalhos universitários e das discussões acadêmicas, seja politicamente na tomada de posição em defesa da universidade pública e da valorização da atividade docente. Disso dá prova o editorial com que apresentou Tempo Social, de que foi um dos fundadores e editor responsável, expondo os objetivos da revista:

"fidelidade a certos valores e ideais orientadores da vida universitária: reflexão incessante sobre os princípios e pressupostos do conhecimento, cultivo das formas mais elaboradas de pensamento, empenho na análise e compreensão de todas as expressões da vida humana, diálogo prudente e permanente com a modernidade, independência frente às solicitações mais imediatistas das várias forças sociais e políticas, crítica serena mas firme perante as injustiças de toda ordem. Numa palavra, compromisso com a verdade, a objetividade e a ciência, fundado na liberdade de pensamento, de pesquisa e de expressão" (Bruni, 1989, p. 5).

A preocupação com o despreparo intelectual dos estudantes recém saídos do segundo grau, que thes dificulta sobremaneira acompanhar os cursos nas Humanidades, o levou a produzir um texto de orientação Introdução às técnicas de trabalho intelectual (Como ler) - de maneira a auxiliar os alunos na compreensão dos argumentos e das teses de um autor, na comparação entre autores e na percepção dos diferentes níveis significativos de uma obra de pensamento. Não só isso. Se seus alunos o respeitam e admiram por suas qualidades didáticas incontestes e por sua dedicação, também seus colegas são capazes de perceber suas contribuições maiores ao ensino das Ciências Sociais: em primeiro lugar, a relação entre 
seu trabalho de pesquisa e o de docência - como se viu nos cursos em que, retomando seu doutoramento, apresentou o nascimento da sociologia no contexto histórico do séc. XIX; em segundo, a introdução de outros pensadores alemães nos cursos de Sociologia, como Simmel (pois, afinal, o pensamento sociológico alemão não se limita a Weber!); e, em terceiro, o diálogo entre filosofia e sociologia — como aconteceu nos cursos sobre Nietzsche.

A docência cultivada por José Carlos Bruni é formadora: não pontifica decretando "faça como eu", mas dialoga dizendo "faça comigo". Nela, os estudantes são iniciados ao mundo da cultura, ao exercício da reflexão e da crítica, à aguda percepção da violência e da luta contra ela, à descoberta dos procedimentos visíveis e invisíveis de criação teórica e da dialética das operações ideológicas de inversão do instituinte no instituído, bem como das práticas políticas para bloquear e reprimir o trabalho de pensamento, e à defesa intransigente da liberdade de pensamento e de expressão. Por isso mesmo, ao reunir seu trabalho docente e o de pesquisa, ao desvendar a gênese da forma moderna de exclusão social, cultural e política, exclusão que apanha e pretende destruir a prática docente formadora, Bruni deliberadamente se apresenta sob os traços da personagem sem nome que Mary Shelley criou pela ação de Victor Frankenstein:

"Acima de tudo, a criatura de Victor Frankenstein não possui nome próprio: é designado pelos termos monstro ou demônio. Sua aparência física foge à norma (...). E finalmente, - isto é essencial - é-lhe recusada sistematicamente a fala: sua simples presença provoca pânico nas pessoas que jamais lhe dão oportunidade para se comunicar. Encarna da maneira mais visível possível a exclusão absoluta (...).

Quanto mais procura um meio de minorar seu sofrimento, tanto mais é obrigado a praticar atos que o repugnam (...). Assim, este personagem sem nome nos dá muito a pensar. Não estaria o monstro a nos dizer que a violência com que a diferença é calada é a maior monstruosidade de que o discurso da ordem, da razão, da autoridade, da competência e da ciência positiva é capaz? (...) Não encarnaria essa figura criada pela ciência a monstruosidade interna da ciência que só é possivel ver nessa forma de exterioridade brutal?

Foi tentando colocar-me no lugar do monstro criado por Victor Frankenstein que as páginas deste trabalho foram escritas" (Bruni, 1986).

Se é este o preço a pagar para lançar-se na contra-corrente da universidade operacional, expressão terminal da normalidade, ordem e eficiência positivistas, Bruni também nos ensina que precisamos e podemos 
tomar a palavra não apenas como denúncia, mas como crítica e como conquista do nome próprio pelo pensamento e na ação.

Recebido para publicação em outubro/2000

\section{KEY WORDS: \\ José Carlos Bruni, teaching, \\ university, \\ positivism, \\ sociology, \\ Augusto Comte.}

CHAUÍ, Marilena. The meaning of formative teaching. Tempo Social; Rev. Sociol. USP, S. Paulo, 12(2): 49-54, November 2000.

ABSTRACT: The author draws an intellectual profile of Jose Carlos Bruni stressing his humanistic academic achievement and his interpretation of Augusto Comte's thought in which Bruni reconstructs the question of order and authoritarianism in modernity.

\section{REFERÊNCIASBIBUOGRÁFICAS}

BRUNI, José Carlos. (1986) Memorial. Faculdade de Filosofia, Letras e Ciências Humanas da Universidade de São Paulo.

. (1989) Apresentação. Tempo Social, São Paulo, 1(1):5, 1o semestre. 